ORIGINAL ARTICLE

\title{
Characteristics of neonates with isolated rectal bleeding
}

\author{
A Maayan-Metzger, N Ghanem, R Mazkereth, J Kuint
}

Arch Dis Child Fetal Neonatal Ed 2004;89:F68-F70

See end of article for authors' affiliations ....................

Correspondence to: Dr Maayan-Metzger, Department of Neonatology, Sheba Medical Center, Sheba 52621 , Israel; Maayan@post.tau.ac.il

Accepted 5 March 2003

\begin{abstract}
Objective: To determine the characteristics of full term and preterm neonates with isolated rectal bleeding (IRB), and to follow the outcome of these low risk patients.

Design: A retrospective case-control study consisting of 147 cases ( 83 full term and near term infants and 64 preterm infants) and 147 controls in a single institution.

Results: A feeding regimen that did not include breast milk was the only variable found to predict IRB. In full term and near term babies (gestational age $\geqslant 35$ weeks), $52.6 \%$ of the study group were breast fed compared with $83.1 \%$ of the controls ( $p<0.0001$ ). In preterm babies (gestational age $\leqslant 34$ weeks), $45.9 \%$ of the study group were breast fed compared with $74.2 \%$ of the controls $(p=0.0014)$. No obvious systemic infection cause was detected. None of the patients showed clinical or radiological deterioration in the days after diagnosis of IRB.

Conclusions: The outcome of a group of low risk neonates with IRB was excellent. It is questionable whether antibiotic treatment is required and feeding needs to be stopped. Breast feeding, even if only partial, should be encouraged.
\end{abstract}

R ectal bleeding in full term and preterm babies is a symptom with a variety of possible causes, among them serious diseases such as necrotising enterocolitis, Hirschprung's disease with enterocolitis, infection colitis, and haemorrhagic disease of newborn. Milder causes for isolated rectal bleeding (IRB) in otherwise asymptomatic babies are allergic proctocolitis, anal fissure, and swallowing blood syndrome. ${ }^{12}$ IRB in otherwise asymptomatic babies is often observed in neonatal departments. In such cases, most nurseries perform a routine screen for bacterial infection, including white blood cell count, blood and stool cultures, and abdominal radiograph. Feeding is discontinued and antibiotic treatment is given regardless of the baby's unalarming appearance and normal laboratory and radiographic findings. The aim of this study was to determine the risk factors for IRB in neonates and to follow up the outcome of these low risk babies.

\section{METHODS}

Medical charts were reviewed for all term and preterm neonates born at the Sheba Medical Center between 1 January 1996 and 31 December 2001 who had subsequently presented with rectal bleeding during their stay in our nursery. IRB was defined as any overt rectal bleeding without haematemesis, and it usually presented as a bloody stool. So that only low risk babies were investigated, the criteria for inclusion were healthy full term and preterm babies who, other than rectal bleeding, showed no clinical manifestations, such as signs of sepsis, distended abdomen, apathy, apnoea or bradycardia, and whose physical examination was normal on diagnosis of the rectal bleeding event. The standard work up for neonates presenting with bloody stool in our nursery includes abdominal radiograph, blood and stool cultures, and white blood cell count. Feeding is discontinued for one to three days, depending on the duration of the bloody stool excretion. In the study group, we included only patients with normal abdominal radiographs. Exclusion criteria were major congenital malformations and special medical treatment, such as assisted ventilation, indomethacin, or oxygen, at the time of onset of IRB. Healthy infants receiving antibiotic treatment for maternal fever and suspected amnionitis were included in the study.
Details recorded included gestational age, birth weight, maternal diseases (chronic conditions, such as hypothyroidism, hypertension, epilepsy, mitral valve prolapse, and systemic lupus erythematosus, and diseases of pregnancy, such as gestational diabetes and pregnancy induced hypertension) and drugs used during pregnancy, time of premature rupture of membranes (PROM), mode of delivery, Apgar score, medical treatment given before the event, and feeding mode. In addition, details on the bloody stool event were recorded, including age at event, duration, laboratory data, and culture results.

A total of 183 medical records were reviewed. Nine were excluded because symptoms other than rectal bleeding were present (distended abdomen, dyspnoea, apnoea, and bradycardia), and four had major congenital malformations. Twenty three babies were excluded because of missing data.

The remaining 147 babies met the inclusion criteria. Two groups were defined: $(a)$ term or near term babies (gestational age $\geqslant 35$ weeks) and $(b)$ preterm babies (gestational age $\leqslant 34$ weeks).

For each patient included in the study, we matched a control, a baby born at the same gestational age and at a time close to the time of birth of the baby in the study group. The medical charts of the control babies were reviewed for birth weight, maternal diseases and medications during pregnancy, time of PROM, mode of delivery, Apgar score, medical treatment, and feeding mode. Feeding mode was defined as breast feeding if it comprised $25 \%$ or more breast milk (at least two breast feeds out of eight feeds a day). We think that feeding consisting of $25 \%$ or more breast feeds is of clinical significance. It is the policy of our department to encourage the use of breast milk for both term and preterm babies. In full term babies, breast feeding is initiated as soon as possible depending on the wellbeing of the mother and child. In cases in which mothers insist on formula supplementation, feeding is increased by $10 \mathrm{ml}$ increments per feed per day during the first week of life and then ad lib. In preterm babies, feeding is

Abbreviations: IRB, isolated rectal bleeding; PROM, premature rupture of membranes 
initiated as soon as possible after their clinical condition has been stabilised. Infants born before 34 weeks gestation are fed by orogastric tube, and feeds are increased by $1-10 \mathrm{ml}$ increments according to their birth weight. We use only freshly expressed breast milk, usually augmented with human milk fortifier (Enfamil HMF; Mead Johnson, Ottawa, Ontario, Canada) from the second week of life.

The study was approved by the research ethics committee of our institution.

\section{Statistical analysis}

The data were analysed using BMDP. ${ }^{3}$ To determine associations between categorical variables and the study variable, we used Pearson's $\chi^{2}$ test and Fisher's exact test, as appropriate. Continuous variables were analysed by analysis of variance. Logistic regression was used to determine those variables that were most significantly associated with IRB. $p \leqslant 0.05$ was considered significant.

\section{RESULTS}

Of 49705 infants born in our hospital during the study period, $183(0.37 \%)$ had rectal bleeding; of these, 147 met the study criteria and were included.

No significant differences were recorded between full term and near term babies in the study and controls with regard to birth weight, sex, mode of delivery, maternal pregnancy diseases and treatment, time of PROM, Apgar score at one and five minutes, and rate of antibiotic treatment before the bleeding episode in the first 3 days of life. A significant difference between the study and the control groups was found in feeding mode. Breast feeding (at least 25\% breast milk) was significantly more common in the control group than the study group $(83.1 \%$ $52.6 \%$ respectively, $\mathrm{p}<0.0001$; table 1$)$. Only nine $(10.8 \%)$ of the full term babies in the study group were totally breast fed, compared with eight infants $(9.6 \%)$ in the control group. In the preterm study group, only three were fully breast fed compared with none in the control group. Because this group of exclusively breast fed infants was too small, two other groups were compared: a group in which feeding included two feeds or more of breast milk and an exclusively formula fed group.

Table 2 shows the clinical and laboratory data for the full and near term study group. White blood cell and platelets counts were in the normal range in these asymptomatic babies with IRB. In five patients, blood cultures were positive,

Table 1 Data for neonates of gestational age $\geqslant 35$ weeks with asymptomatic bloody stool compared with controls

\begin{tabular}{llll}
\hline & $\begin{array}{l}\text { Study group } \\
(\mathbf{n}=83)\end{array}$ & $\begin{array}{l}\text { Control group } \\
(\mathbf{n}=\mathbf{8 3})\end{array}$ & $\mathrm{p}$ Value \\
\hline Gestational age (weeks) & $39(35-42)$ & $39(35-42)$ & $\mathrm{NS}$ \\
Birth weight (g) & 3120 & 2995 & $\mathrm{NS}$ \\
& $(1465-4610)$ & $(1830-4175)$ & \\
\% Male/female & $51.8 / 48.2$ & $48 . \tilde{8} / 51.2$ & $\mathrm{NS}$ \\
Apgar at 1 min & $9(1-9)$ & $9(7-10)$ & $\mathrm{NS}$ \\
Partum spontaneous labour & $52(63)$ & $55(66.7)$ & $\mathrm{NS}$ \\
Maternal chronic disease & $11(12.8)$ & $6(7.1)$ & $\mathrm{NS}$ \\
Maternal pregnancy disease & $16(19.7)$ & $6(7.1)$ & $\mathrm{NS}$ \\
Drugs used in pregnancy & $5(6.6)$ & $4(4.8)$ & $\mathrm{NS}$ \\
Maternal fever & $6(6.9)$ & $2(2.4)$ & $\mathrm{NS}$ \\
Maternal antibiotic treatment & $8(9.5)$ & $11(13.1)$ & $\mathrm{NS}$ \\
PROM $>12$ hours & $9(10.5)$ & $10(12)$ & $\mathrm{NS}$ \\
Antibiotic treatment in first & $17(20.7)$ & $16(20)$ & $\mathrm{NS}$ \\
3 days of life & & & \\
Breast milk nutrition & $40(52.6)$ & $69(83.1)$ & $<0.0001$ \\
\hline
\end{tabular}

Values are either median (range) or number (\%) unless otherwise indicated.

PROM, Premature rupture of membranes.

\begin{tabular}{|c|c|}
\hline & Results \\
\hline Age at event (days) & $4(1-14)$ \\
\hline WBC $(1000 / \mu \mathrm{l})$ & $11565(5220-25700)$ \\
\hline Platelets $(1000 / \mu l)$ & $\begin{array}{l}308000(112000- \\
538000)\end{array}$ \\
\hline Duration of bloody stool (days) & $1(1-3)$ \\
\hline Time without feeds (days) & $2(0-6)$ \\
\hline $\begin{array}{l}\text { Length of antibiotic treatment } \\
\text { (days) }\end{array}$ & $4(0-7)$ \\
\hline $\begin{array}{l}\text { Patients with positive blood } \\
\text { cultures }\end{array}$ & $4(4.7)$ \\
\hline $\begin{array}{l}\text { Patients with positive stool } \\
\text { cultures }\end{array}$ & $5(6)$ \\
\hline
\end{tabular}

with three instances of growth of coagulase negative staphylococcus, and in two patients mixed bacterial growth was present. All these cultures were considered contaminated as antibiotic treatment given was not specific for these pathogens and subsequent blood cultures were negative. Five stool cultures were positive, showing growth of campylobacter in three patients, and Escherichia coli and Shigella sonnei in one patient each.

No differences were recorded between study and control groups of preterms with respect to birth weight, sex, mode of delivery, maternal pregnancy diseases and treatment, time of PROM, and Apgar score at one and five minutes. There were no differences in the need for ventilation or oxygen before the bloody stool event. Breast feeding was significantly more common in preterms in the control group $(46 ; 74.2 \%)$ than in those in the study group $(28 ; 45.9 \%)(\mathrm{p}=0.0014)$ (table 3$)$.

Table 4 shows the data for the preterm study group. White blood cell and platelet count in all patients were within the normal range. In two patients, blood culture was positive for coagulase negative staphylococcus and considered contaminated, and one patient had a positive blood culture for corynbacterium.

Five positive stool cultures (enterococcus, E coli, campylobacter, echo virus, and rotavirus) were recorded in five other patients in the study group.

Table 3 Data for preterm babies at gestational age $\leqslant 34$ weeks with asymptomatic bloody stool compared with controls

\begin{tabular}{|c|c|c|c|}
\hline & $\begin{array}{l}\text { Study group } \\
(n=64)\end{array}$ & $\begin{array}{l}\text { Control group } \\
(n=64)\end{array}$ & p Value \\
\hline Gestational age (weeks) & $32(26-34)$ & $32(26-34)$ & NS \\
\hline Birth weight $(\mathrm{g})$ & $\begin{array}{l}1645 \\
(885-2660)\end{array}$ & $\begin{array}{l}1727 \\
(684-2715)\end{array}$ & NS \\
\hline$\%$ Male/female & $39.1 / 60.9$ & $54.8 / 45.2$ & NS \\
\hline Apgar at $1 \mathrm{~min}$ & $9(3-9)$ & $8(3-9)$ & NS \\
\hline Partum spontaneous labour & $31(49.1)$ & $33(51.7)$ & NS \\
\hline Maternal chronic disease & $9(14.3)$ & $7(11.3)$ & NS \\
\hline $\begin{array}{l}\text { Maternal pregnancy } \\
\text { disease }\end{array}$ & $22(36.1)$ & $20(32.3)$ & NS \\
\hline Drugs used in pregnancy & $6(9.6)$ & $2(3.2)$ & NS \\
\hline Maternal fever & $10(16.4)$ & $6(9.7)$ & NS \\
\hline Antenatal steroid treatment & 49 (76.2) & $51(80.4)$ & NS \\
\hline Assisted ventilation & $15(22.8)$ & $22(35)$ & NS \\
\hline Oxygen treatment & $26(40.4)$ & $29(45)$ & NS \\
\hline $\begin{array}{l}\text { Antibiotic treatment before } \\
\text { event }\end{array}$ & $47(73.4)$ & 53 (85.7) & NS \\
\hline Breast milk nutrition & $28(45.9)$ & $46(74.2)$ & 0.0014 \\
\hline
\end{tabular}




\begin{tabular}{|c|c|}
\hline & Results \\
\hline $\begin{array}{l}\text { Age at event (days) } \\
\text { WBC }(1000 / \mu l) \\
\text { Platelets }(1000 / \mu l)\end{array}$ & $\begin{array}{l}16(2-73) \\
10890(5390-18200) \\
408000(130000- \\
1000400)\end{array}$ \\
\hline $\begin{array}{l}\text { Duration of bloody stool (days) } \\
\text { Time without feeds (days) }\end{array}$ & $\begin{array}{l}1(1-2) \\
3(1-7)\end{array}$ \\
\hline $\begin{array}{l}\text { Length of antibiotic treatment } \\
\text { (days) }\end{array}$ & $5(0-11)$ \\
\hline $\begin{array}{l}\text { Patients with positive blood } \\
\text { cultures }\end{array}$ & $4(6.5)$ \\
\hline $\begin{array}{l}\text { Patients with positive stool } \\
\text { cultures }\end{array}$ & $5(7.8)$ \\
\hline
\end{tabular}

Values are either median (range) or number (\%). WBC, White blood cell count.

Using logistic regression, which included gestational age, birth weight, pregnancy diseases, and type of feeding, we found that feeding was the only predictive variable for bloody stool, with an odds ratio of 4.11 and $95 \%$ confidence interval of 2.41 to 6.99. In other words, babies of mothers who did not breast feed at all (less than $25 \%$ of breast milk) had a 4.1 times greater chance of having IRB.

\section{DISCUSSION}

Our study found that none of the perinatal factors, including maternal diseases and drugs used during pregnancy, were associated with increased risk of IRB, nor were neonatal diseases and medical treatment. The only factor differentiating study babies from controls was the lower rates of breast feeding in the study group. All positive blood cultures in the study group were considered contaminated.

In all cases, the duration of IRB was several days, rarely exceeding three. None of the patients showed clinical or radiological deterioration in the days after diagnosis of IRB.

Rectal bleeding in neonates can have several causes.

(1) Immunological mechanism. An inflammatory reaction can be caused by intestinal intolerance to foreign proteins ${ }^{45}$ in exclusively breast fed infants as well, where it was presumed that the allergic reaction is due to cow milk proteins absorbed in the maternal diet and transferred through the breast milk to the baby. ${ }^{5-7}$ Rectosigmoidoscopy performed in some studies revealed an inflammatory reaction to eosinophilic infiltrates. These babies are otherwise asymptomatic, and other allergic manifestations are rare in the neonatal period. The protective effect of breast milk was shown. It was suggested that breast milk may modulate secretory IgA production, preventing transition of macromolecules across the immature gut and so blocking the immune response to these proteins. ${ }^{8}{ }^{9}$ Immunological irritation of the intestine may be the pathogenesis in several of the babies in our study. However, as our nursery policy is not to automatically change the type of feeding in response to a single episode of IRB and as there was only one recurrent episode of IRB in the study group, this mechanism remains questionable.

(2) Infection. The intestinal flora in breast fed babies differs from that in babies not breast fed, ${ }^{10}{ }^{11}$ with a clear promotion of the growth of bifidobacteria and suppression of pathogenic enterobacteria in breast fed infants. ${ }^{11}$ In babies of very low birth weight, late colonisation with bifidobacteria has been detected. ${ }^{12}$ This may explain the later clinical appearance of rectal bleeding in preterm infants. Although stool cultures were positive (mostly enterobacteria) for 10 patients in our study, no specific antibiotic treatment was given. Moreover, the stool cultures came out positive after five days, when the patients were already asymptomatic and recovery had occurred, as indicated by negative repeated stool cultures. All positive blood cultures were considered contaminated, and repeated blood cultures came out sterile for all patients with positive blood cultures. All cases were sporadic. It can be assumed that infection is not a very common cause of IRB.

(3) Swallowing blood syndrome may be a cause of IRB in breast fed babies. It can be ruled out in the preterm group, as feeding is by either bottle or nasogastric tube. In full term babies, maternal nipples are checked to rule out this source of bleeding.

(4) Anal fissure is thought to be a common cause of rectal bleeding in early childhood. ${ }^{1}$ However, it was excluded in our group of patients.

(5) Necrotising enterocolitis is the most disturbing cause of IRB, especially in preterm infants. In patients with IRB but normal clinical and radiological findings, necrotising enterocolitis can be safely excluded.

The advantages of breast milk in preventing intestinal diseases in term and preterm infants by immunological, allergic, and/or infection pathways are well established. ${ }^{13}$ Our study confirms this finding regardless of IRB cause.

In conclusion, the pathogenesis of IRB in full term and preterm infants is not fully understood. Postnatal changes such as feeding and bacterial colonisation may be the only explanation for IRB. No obvious risk factors were detected, but breast feeding, even if intermittent, showed a protective effect. We believe the phenomenon of IRB is benign. After careful physical examination, sepsis work up, and abdominal radiograph, some may consider that any further treatmentfor example, antibiotics and cessation of feeding-is unnecessary, although it has been our policy so far.

Further studies are required to determine whether changes in type of feeding are necessary.

\section{Authors' affiliations}

A Maayan-Metzger, N Ghanem, R Mazkereth, J Kuint, Department of Neonatology, Sheba Medical Center, and Sackler Faculty of Medicine, Tel Aviv University, Tel Aviv, Israel

\section{REFERENCES}

1 Thompson EC, Brown MF, Bowen EC, et al. Causes of gastrointestinal hemorrhage in neonates and children. South Med J 1996;89:370-4. 2 Levene MI. Rectal bleeding in the first month of life. Postgrad Med J 1979;55:22-3.

3 BMDP. BMDP statistical software, In: Dixon WJ, chief ed. Los Angeles: University of California Press, 1992.

4 Dupont C, Badoual J, Le Luyer B, et al. Rectosigmoidoscopic findings during isolated rectal bleeding in the neonate. J Pediatr Gastroenterol Nutr 1987:6:257-64.

5 Lake AM. Food-induced eosinophilic proctocolitis. J Pediatr Gastroenterol Nutr 2000;30(suppl):S58-60.

6 Anveden-Hertzberg L, Finkel Y, Sandstedt B, et al. Proctocolitis in exclusively breast-fed infants. Eur J Pediatr 1996;155:464-7.

7 Kilshaw PJ, Cant AJ. The passage of maternal dietary proteins into human breast milk. Int Arch Allergy Appl Immunol 1984;75:8-15.

8 Walker WA, Isselbacher KJ. Uptake and transport of macromolecules by the intestine: possible role in clinical disorders. Gastroenterology 1974;67:531.

9 Walker WA. Host defense mechanisms in the gastrointestinal tract. Pediatrics 1976;57:901.

10 Benno Y, Sawada K, Mitsuoka T. The intestinal microflora of infants: composition of fecal flora in breast-fed and bottle-fed infants. Microbiol Immunol 1984;28:975-86.

11 Yoshioka H, Iseki KI, Fujita K. Development of intestinal flora in the neonatal period in breast-fed and bottle-fed infants. Pediatrics 1983;72:317-21.

12 Sakata H, Yoshioka H, Fujita K. Development of the intestinal flora in very low birth weight infants compared to normal full-term newborns. Eur J Pediatr 1985; 144:186-90

13 Lucas A, Cole TJ. Breast milk and neonatal necrotizing enterocolitis. Lancet 1990;336:1519-23. 